\title{
Embedding Knowledge Management Theory in Learning and Teaching Approach
}

\author{
Fahmi Ibrahim (Corresponding author) \\ School of Business \\ Universiti Teknologi Brunei \\ Brunei Darussalam \\ E-mail: fahmi.ibrahim@utb.edu.bn \\ Noor Maya Salleh \\ School of Business \\ Universiti Teknologi Brunei \\ Brunei Darussalam \\ E-mail: noormaya.salleh@utb.edu.bn
}

Received: October 18, 2018

doi:10.5296/ijld.v9i1.13786
Accepted: January 7, 2019 Published: January 24, 2019

URL: https://doi.org/10.5296/ijld.v9i1.13786

\begin{abstract}
The article focuses on the role of management of knowledge can have on organisations and looks at practical knowledge management $(\mathrm{KM})$ practices from industry that can be employed by educational institutions. There is a view that $\mathrm{KM}$ is primarily business concept that can provide competitive advantage for commercial organisations. However, the KM processes such as knowledge creation, capture, sharing and use are not exclusive to business; good KM practices can bring benefits to all organisations. While KM is a growing field in almost last 20 years, very little has been written about it in the educational context. This is surprising, considering that education is about the creation and application of knowledge. Given that higher education institution's (HEI) priority of developing and creating knowledge, an integrated approach that prioritise KM can be used to underpin university's organisational processes particularly its learning and teaching approach. This article illustrates how attention to two main perspectives exists in KM field; objectivist perspective and practice-based perspective, can inform the learning and teaching approach; surface and deep approach. The approach of this paper is basically conceptual and descriptive. Drawing from empirical
\end{abstract}


research in UK car manufacturing industry, the article is to address the way in which KM practices are being implemented and elaborates on the need the KM in teaching-learning process. This suggests an integrated approach to provide for a balanced strategy in terms of $\mathrm{KM}$ implementation that can be applied in HEI. It is important for educators in HEI to understand how certain KM perspective and influence can lead to different to different learning and teaching strategy. Thus, HEI can realise the potential of KM in order to enhance the learning of students.

Keywords: Knowledge management, surface and deep learning, higher education

\section{Introduction}

Over the past decade, KM has come into the limelight and received considerable attention from academics and practitioners. In relation to this phenomenon, Grant (2001:p.27) suggests that 'among the innovations that have swept through the world of management during the past two decades......KM has probably aroused the greatest interest and made the biggest impact'. The most significant factor of this phenomenon is the recognition of the importance of knowledge as a critical resource for organisations (Drucker, 1998; Nonaka, 1991; Davenport and Prusak, 1998; Prusak, 1997; Leornard-Barton, 1995). Thus, knowledge is claimed as the main distinguishing factor of business success and competitive advantage (Carlucci and Schiuma, 2006; Pan \& Scarborough, 1999). Moreover, the environmental change has led to a new perspective in management thinking to recognise knowledge as a strategic asset and a source of competitive advantage (Leonard Barton, 1995; Nonaka, 1991; Grant, 1996) which appears to follow a significant shift in the business environment from an industrial economy to the new economy. The fundamental principles underlying this new economy are dramatically different to the traditional concepts of how value is created to make organisations successful. The fundamental principle has shifted from relying on classical factors of production, such as land, labour and capital to 'knowledge' as a primary resource for the new economy (Drucker, 1994). It is argued that in the new economy knowledge can replicate and multiply endlessly, while material resources cannot; natural resources deplete with use, but knowledge expands with use (Alee, 1999). Nevertheless, there is considerable ambiguity in the KM terminology, which has led to fragmented debate on the topic (Bollinger and Smith, 2001). Despite the ambiguity of the terminology and the fragmented debate on the subject area, the experiences of many organisations documented in the literature provide evidence that it is vital for organisations to embrace, adopt and implement KM practices in order to achieve their organisational objectives. These organisations include Booz Allen \& Hamilton (General Consulting), BP's Virtual Team Project (Oil \& Gas), Daimler-Chrysler (Automobile) and Hoffman-LaRoche (Pharmaceutical) (Sheehan \& Poole, 2005). Hence, it is argued that KM is a complex area that brings together hard, soft and abstract aspects; IT issues related to KM tools, organisational issues related to culture, as well as fundamental philosophical issues with regard to different epistemological views of knowledge. This often results in the implementation of KM initiatives with either an overemphasis on technology (hard aspects) to the exclusion of adequate people management (soft aspects) or strong people management programmes hindered by inadequate enabling technologies (Moffett et al., 2003:p. 6). 


\section{Macrothink}

International Journal of Learning and Development

ISSN 2164-4063

2019, Vol. 9, No. 1

Against this backdrop, successful of KM implementation within an organisation has a great role to play. Universities and other higher education institutions (HEI) are recognised to be in knowledge business (Goddrad, 1998) and increasingly they are exposed to marketplace pressures in a similar way to other businesses. It might be reasonable that KM have something offer HEI (Rowley, 2000). Teaching and learning process in HIE is dominated by classroom teaching based and text book content. Knowledge produced in the process of course preparation and delivery is colossal and it is required that collaborative effort is pooled in to maintain this knowledge as an institutional resource (Bushry and Ranjan, 2012). This will facilitate not only new faculty in preparing for a course, but also help students to augment their knowledge.

Learning for reuse of 'explicit knowledge' in the teaching process is a common phenomenon in academia. The most common methodology employed for such reusable learning is the identification of suitable resources on the web through search engines and the cut and paste technique to produce the teaching material. It is claimed that no teaching strategy can fully replace classroom teaching, but restricting the teaching process only to the delivery of content from textbooks purely from explicit knowledge may not be entirely sufficient in today's competitive scenario. The textbook explicit knowledge needs to be supplemented with ideas from research and industry trends as well as enriched through practice and "tacit knowledge beyond the book".

This article invokes the idea of a conceptual framework for knowledge management (KM) in teaching-learning process in HEI. It aaddresses the way in which KM practices are being implemented so as to suggest a strategy that may promise the most appropriate approach for effective KM implementation in HIE. Experience in adoption and implementation of KM in other knowledge-based organisations such UK car manufacturing industry is discussed, as a background to explore the validity of the concept of $\mathrm{KM}$ and the consequences of its implementation in universities.

\section{Knowledge Management Perspectives}

In this section, a brief summary of selected $\mathrm{KM}$ literature related to main issues of $\mathrm{KM}$ practices in two different perspectives is discussed. This is central in order to provide a theoretical background for developing the proposed conceptual framework. For the purpose of this study, knowledge is defined based on two broad epistemological camps in the contemporary debate on the nature of knowledge, identified by Hislop (2005:p.14): objectivist perspective (explicit knowledge) and practice-based perspective (tacit knowledge). For example, authors such Cook and Brown (1999) and Asudani (2005), refer to the objectivist perspective as epistemology of possession, where knowledge is regarded as an asset (Empson, 2001), 'stock' (Fahey and Prusak, 1998) and static (Newell et al., 2002). Such knowledge can exist in the form of documents, operating procedures, computer systems or databases. On the other hand, the practice-based perspective conceptualises knowledge as socially constructed and inherently tacit. This perspective is labelled as 'epistemology of practice' (Cook and Brown ,1999) where knowledge is regarded as 'flow' (Fahey and Prusak, 1998) and process (Empson, 2001). The central issue of this perspective is that knowledge resides in the human 
mind and is dependent on the knower (Venzin et al., 1998). These perspectives, in turn, not only provide an insight into how the nature of knowledge has been conceptualised, but also provides the roots of KM practices, based on the different assumptions of knowledge.

For instance for KM practice - objectivist perspective, there is an acknowledgement that much of organisational knowledge may be tacit and it is possible to convert this knowledge into explicit form. For example, all the instructions for operating machines may not be totally explicit but, with the expertise and experience of workers operating them, it is possible to make all the knowledge explicit and codify it into a complete set of standard operating procedures. The primary role of this kind of KM perspective is to allow knowledge to be shared widely and effectively within or across organisations, so that best practices, problem solutions and procedures can be shared. Technology, includes hardware, software or other means of processing, storing, capturing and organising data or information plays a major role in this KM process. The characteristics of this KM perspective can be defined as the first generation KM (McElroy, 2003:p.xxiv) as there was strong emphasis on IT in many of the earliest KM initiatives. This has become known as the 'supply side of KM' which consists of capturing, codifying, and sharing valuable knowledge, and also involves getting the right information to the right people at the right time.

In contrast to objectivist perspective, the practice-based perspective conceptualises knowledge not as a codifiable entity, but instead emphasises that knowledge is socially constructed and is inherently tacit. This perspective defines knowledge in dynamic terms, regarding it as a practice of doing or knowing rather than static or objective- knowledge which people possess (Newell et al., 2002:p.7). Cook and Brown (1999) labelled this perspective as an 'epistemology of practice' due to the centrality of human activity to its conception of knowledge. In other words, knowledge resides in mind, body and social systems, which are dependent on the context and the knower (Venzin et al., 1998:p.43). Therefore, the nature of knowledge which is rooted and manifested in the human mind and activity represents the characteristics of knowledge from a practice-based perspective. As noted by Hislop (2005:p.29-34) that tacit and explicit knowledge are inseparable. They are not two ends of a continuum, but two sides of the same coin (Tsoukas, 2005: p.158). The consequence is that there is no such thing as completely explicit knowledge, as all knowledge will have a tacit dimension or will remain tacit, and therefore resistant to articulation or codification (Newell et al., 2002:p.7). Thus, the view of explicit knowledge which stands on its own, would reduce the ineffability of tacit knowledge and narrow all knowledge to only what can be articulated (Tsoukas, 2005:p.158). In view of that, from this perspective, it is impossible to totally codify knowledge into fully explicit form. There will be an element of tacit knowledge which is still embodied in people. The practice-based perspective argues that all knowledge is socially constructed which is purely subjective to interpretations from people. A general model of KM practice-based perspective is focused on knowledge sharing through rich interactions, knowledge sharing culture that motivating people to share knowledge instead of hoarding their knowledge by establishing networked relationship and trust (Davenport and Prusak, 1998).

Nonaka's SECI Process: Four Modes of Knowledge Conversion is established frameworks that have been developed that distinguish different types or perspectives of knowledge. Nonaka and 


\section{Macrothink}

International Journal of Learning and Development

ISSN 2164-4063

2019, Vol. 9, No. 1

Takeuchi (1995) identified four different processes through which knowledge is created and applied; socialization through a process from tacit to tacit knowledge; externalization through a process of tacit to explicit knowledge; combination through a process of explicit to explicit knowledge; internalization through a process of explicit to tacit knowledge.

Socialization is the process of converting tacit knowledge through shared experience. For example socialization may occur in traditional apprenticeships where apprentices learn the tacit knowledge needed by being exposed to hands-on experience, rather than from manuals. The process of articulating or codifying tacit knowledge as explicit knowledge is externalization. The concept of generating ideas for process improvement by articulating it as standard operating procedures is an example of this process. Combination is the process of converting explicit knowledge into more systematic sets of explicit knowledge. For example, a production manager of a company collects information from throughout the organisation and puts it together in the context of a production performance report, and that report is new knowledge created. Via internalization, explicit knowledge created is shared throughout an organisation and converted into tacit knowledge by individuals. Internalization is related to 'learning by doing' for example, trainees internalize explicit knowledge by reading documents and manuals about their jobs and reflecting on them to enrich their tacit knowledge in experiments or simulations. Nevertheless, these processes of knowledge conversion from the original model have been criticised because they can only occur at the level of the individual (Newell et al., 2002) in promoting creativity and innovation. Further, the framework implies that knowledge is deeply ingrained in an objectivist perspective type of knowledge, which is static, non-humanistic and non-contextual. Nonetheless, Nonaka et al. (2001) refined the framework in a further development by introducing the ' $b a$ ' concept, which is defined as a 'shared context' where knowledge is shared, created and utilised. The concept suggests that knowledge is dynamic, as it is created in social interaction among individuals and groups/organisations; knowledge is subjective, because it is related to human action; and knowledge needs context to be created. In summary, the concept shows organisations how to manage the dynamic process of knowledge creation, which is characterised by different types of knowledge. Having established both the fundamental of KM perspectives, it provides the roots the dimension of approaches to KM that is discussed in the following section.

\section{Dimension of Approaches to Knowledge Management}

Following the discussions in previous section, a significant proportion of the contemporary literature suggests that the approaches which are used for KM implementation can be classified into two dominant categories based on objectivist and practiced-based perspective dichotomy. Focussing on these categories, two very different approaches for KM implementation have emerged, so-called IT and people involvement approach. This view is in line to that of Hansen et. al (1999), who contend that the personalisation strategy (people involvement approach) is an approach where knowledge is closely embedded to the person who develops it and shares through face-to-face interaction, while in codification strategy (IT approach) knowledge is codified and stored in databases, where it can be assessed and retrieved easily by anyone in the organisation. Drawing from the existing literature, two dimensions of approaches to KM are discussed in following sub-sections. 
A common theme in KM literature is the important role of information technology (IT). IT had a central place and plays a prominent role in the early KM initiatives. It is important to note that IT consists of combination of hardware and software technologies (Ruikar et al., 2007). Hardware technologies and components are important for a KM implementation as they are the medium for storage and transfer knowledge i.e. personal computers. On the other hand, software technologies play an important part in facilitating the implementation of KM. Software applications provided by software vendors take many forms and perform many tasks. However, the role of IT (both hardware and software) in KM rests predominantly on the key assumptions of the objectivist perspective or practice-based perspective - that were previously discussed in previous section. Building on the assumptions of the objectivist perspective, organisations believe that IT can play a direct role in the KM process. In other words, IT is a 'driver' of KM practices. Yet, IT simply acts as a medium to search, codify, categorise, store and share explicit knowledge (Hislop, 2005:p.108). For example, one common use of search engines is for finding best practices within directories of databases. Another example would be where computer aided design (CAD) systems are used to design new products. So, in principle, IT seems to offer people and the organisations for which they work - faster, cheaper and broader sources of data and to enable them to generate and share knowledge. Although great claims have been made about the use of IT for KM, there are limitations for such initiatives which rely heavily on IT. There is much more to KM than the technology alone (Sarvary, 1999:p.95). This confirms arguments that there has been far too much reliance on the idea that KM has to do with IT. The problem of over-reliance on IT-driven KM is supported by evidence that there is no direct correlation between IT investment and business performance or KM (Malhorta, 1998; Strassman, 1997). In retrospect, many KM initiative failures are primarily driven by the adoption of technology (Tsui, 2005). Moreover, McDermott (1999) noted that most companies soon find that leveraging knowledge through the use of IT is hard to achieve.

There are five fundamental criticisms of IT in relation to KM practices that focus largely on the objectivist perspective as against the practice-based perspective (Hislop, 2005:p.110). Firstly, the objectivist perspective assumes that all or most relevant knowledge can be made explicit or codifiable whilst the practice-based perspective argues that much tacit knowledge can never be made explicit. Secondly, the objectivist perspective does not acknowledge the inseparable character of tacit and explicit knowledge, which means that there is no tacit dimension at all in explicit knowledge that has been communicated or codified. In other words, the tacit dimension is lost once it has been codified or transferred through IT. Thirdly, it underestimates the extent to which knowledge in organisations is fragmented, dispersed, and specialised. Fourthly, it is argued that over-reliance on IT underestimates the extent to which knowledge is context-specific, which refers to knowledge that is difficult to remove from its context and understand in a different context. Finally, to some extent as a consequence of all the above criticisms, the objectivist perspective is argued to suffer 'synoptic delusion'; the mistaken idea that it is possible to collect an organisation's knowledge in a single repository (Tsoukas, 2005:p.100). 


\section{MInstitute ${ }^{\text {Mink }}$}

The criticisms of the role of IT in KM from an objectivist perspective, have not led to a position where the role of IT is questioned. For example, IT supports knowledge sharing through video conferencing, within or between CoPs, without losing tacitness of knowledge. Therefore, those who emphasise the 'people side' of KM still believe that IT can play a role as an 'enabler' in relation to facilitating and supporting the social relationships, collaborations and communication processes which underpin the KM process. In summary, computer-based systems can be of benefit in knowledge-based activities once such systems are designed to support the development and communication of human meaning (Walsham, 2001:p.599). Moreover, it is suggested that advances in computer technology have the potential to make work more knowledge and skill-intensive through the potential for problem solving (Zuboff, 1988).

Generally, whatever role that IT systems have in KM initiatives, their design and implementation requires to be considered against the practice of the human-based perspective types of KM models that includes the cultural and organisational context within which they are being implemented. The danger of not doing this will lead to the failure of KM initiatives as the great trap in KM is using information management tools and concepts to design KM systems (McDermott, 1999:p.104). Liebowitz (1999a:p.iv) contributes to this view by identifying what he considers to be incorrect linking of KM to the field of information systems, thus neglecting the crucial role of individuals in knowledge activities. The appropriate stance of IT within KM should be as integrator of communications technology, rather than solely as information or knowledge repository (Moffett et al., 2004).

\subsection{Cultural Approach}

The first generation KM initiatives evolved from an interest in IT, which neglected people-related factors. The earliest literature was firmly associated with the objectivist perspective on knowledge, while the second generation KM initiatives emphasised the importance of people involvement factors that developed from the practice-based perspective, as discussed in the previous section on the characteristics of knowledge. This reflects the importance of recognising the organisational culture which has grown significantly in KM initiatives. Fundamentally, this is because the conceptualisation of knowledge takes greater account of people-related issues and views knowledge as largely tacit, socially constructed and, thus, interrelated to the participation of social networks, including CoPs and work groups.

According to Schein (2004), culture can be defined as shared values, beliefs and practices of the people in organisations that refer to 'the ways things are done in the organisation'. It is described further that culture is tightly connected to certain groups of people in organisations who have been working together for a considerable length of time; throughout this period they have developed certain behaviours to deal with and solve problems as well as a collective identity and know-how to work together effectively (Ribiere and Sitar, 2003:p. 40). Based on this definition and description, the primary determinant of $\mathrm{KM}$ is a culture that emphasises and encourages active participation in knowledge sharing. In an organisation with a knowledge sharing culture, people would share ideas and insights because they see it as natural, rather than that something they are forced to do (McDermott and O'Dell, 2001). A range of surveys from 
the study of Ruggles (1998), Management Review (1999), KPMG (2000), Breu et. al (2000) and Edwrads et. al (2000) consistently revealed that the main obstacles to the success of KM initiatives were social and cultural factors.

The conclusion that can be inferred from these results is that the organisations surveyed did not take adequate steps to establish the appropriate cultural factors in their KM initiatives, and instead, they focused on utilising IT. Therefore, appreciating the significance of social and cultural factors is vital in order to make KM initiatives successful. McDermott and O'Dell (2001:p.77) suggest that a successful KM approach should be built to fit with organisational culture. Their study indicates that organisations which attempt to shape the culture to fit their KM initiative are likely to find the initiative fails. As a result, knowledge sharing cultures can be instilled in the organisations depending on the values and the style of the organisations. McDermott and O'Dell (2001:p.78-83) argue that it is necessary for organisations to align their KM initiative with their organisation's culture by linking it to both visible and invisible dimensions of culture (see Table 1.1). For the visible culture dimensions, the KM initiative needs to be focussed on solving practical business problems. It means that the KM initiative should link to business strategy. For example, Pricewaterhouse Coopers has built sharing knowledge into its business strategy and brand identity labelled 'People, knowledge and the world'; knowledge is the link between the company and its customers. They have an extensive and visible organisational structure with a Chief Knowledge Officer (CKO) devoted to championing KM initiatives. The KM approach also needs to match the overall style of the organisation. Some organisations have an official KM programme that emanates from the corporate level, whilst others have small knowledge sharing programmes with a low degree of formality to match the overall environment of the organisation. In the same way, management support throughout the programme is important to making knowledge sharing happen (Benbya and Belbaly, 2005). For instance, if management spends a significant amount of resources on implementing a KM programme, employees could interpret this as a signal of management's support and they act accordingly.

Table 1. The Linkage of Visible and Invisible Organisational Culture with Knowledge Management Initiatives

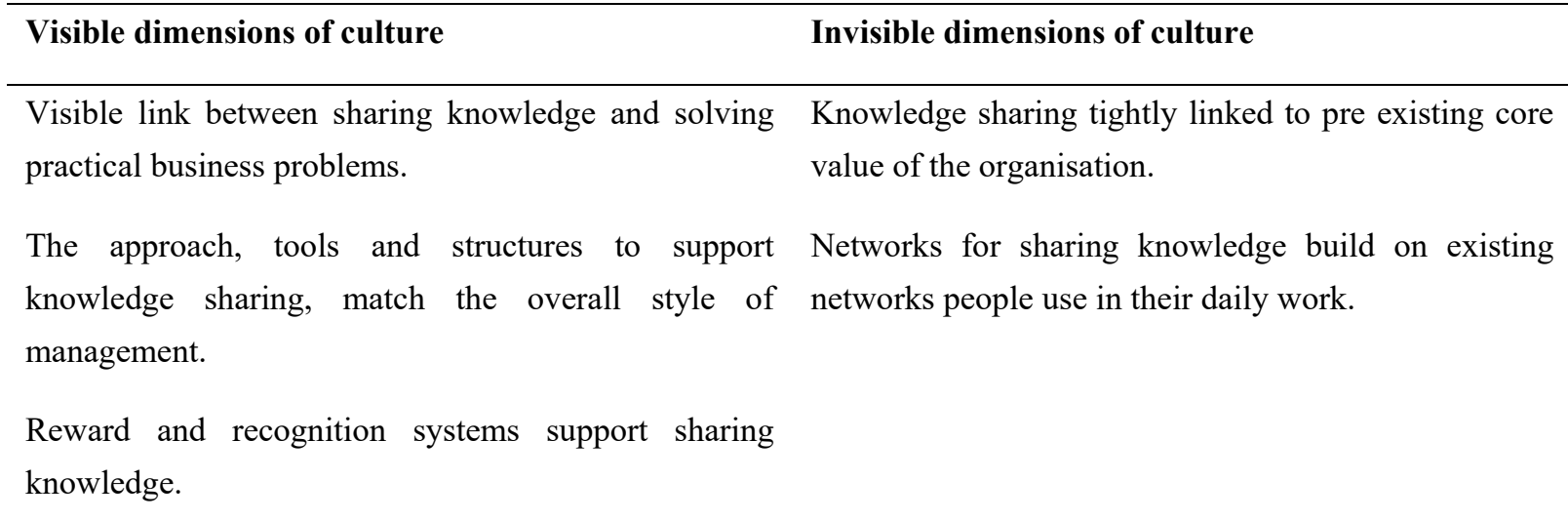




\section{Macrothink}

Finally, the reward and recognition systems should make visible the importance of appropriate knowledge sharing. Davenport (cited in Wah, 1999) suggested that sharing knowledge is usually considered a sideline activity, and employees will only take it seriously when rewards are built into compensation and benefits packages. Further, he noted that 'the best kind of knowledge transfer is informal, but the best way to get knowledge transferred is to reward people for transferring it' (Davenport, quoted in Wah, 1999:p.27). Rewards could range from monetary (extrinsic) incentives, such as bonuses and to non-monetary (intrinsic) incentives, such as dinner gift certificates and rewards, such as praise and public recognition that do not have a monetary equivalent value (Bartol and Srivastava, 2002). Accordingly, people need incentives to participate in the knowledge sharing process (Hansen et al., 1999:p.113).

In terms of the invisible dimensions of knowledge culture, $\mathrm{KM}$ initiatives should be tightly linked to the core values of the organisation. McDermott and O'Dell (2001) found from their study that organisations did not describe knowledge sharing as their 'new direction' or 'change programme', instead they described it as a way of enabling people to pursue the core values of the organisation. 'Involvement' and 'team working' are examples of language that reflects pre-existing cultural core values which are widely held throughout the organisation. Therefore, it will enable people to share their knowledge naturally because they believe in the core values that they have and not because they believe in knowledge sharing itself. This view relates to the requirement to build knowledge sharing networks based on existing networks which are purely social and informal. Most of the informal networks have operated without any formal sanctions and are manifested through informal meetings and even conversation in tea rooms, for example. The members of the networks trust each other and feel obliged to share insights with each other.

The central concept of the McDermott and O'Dell study is that cultural change can be achieved if appropriate knowledge sharing behaviours are a part of the existing culture. However, in other mainstream perspectives in the KM literature, it is suggested that organisational culture can be changed and modified in ways to encourage and support desired knowledge behaviours and attitudes (Ribiere and Sitar, 2003). This is perhaps the most difficult, complex and daunting task because culture is not simply the conscious design of management, but reflects the evolution of the organisation over a period of time (Pan and Scarborough, 1999:p.368). In summary, organisational culture is one of the most important conditions leading to the success or failure of KM initiatives.

\section{Knowledge Management Concepts in Learning and Teaching Process}

In the knowledge based economy, it is claimed that the smartest organisations will survive. They must attract, recruit, train and retain the very best people. One of the best forms of competitive advantage organisations can have is a talented workforce. Organisations have realised that the benefits of implementing KM in order to further educate and train their staff by making individuals more effective at sharing explicit knowledge - IT approach and creation of new ways to expose tacit knowledge - cultural approach (Frappaolo and Wilson Todd, 2000). The most noteworthy is the growing significance of work related learning and the recognition of work and work experience as a key source of learning make continuous learning and 
education necessary for individuals and employees to meet the changing requirement of the marketplace (Psarras, 2006). The nature of work is undergoing of profound change, as Davies (1998) defines;

"Work is increasingly about how knowledge comes to be defined as useful and education itself is viewed as a form of work which can lead to self-realisation and self-fulfilment at individual and existential level"

Today's employees must be inquisitive, have flexible thought process and be open to new ideas. These abilities are required to meet the numerous demands of business and the challenges of technology. On the other hand, students no longer satisfied with first phase education. Their needs are now increasingly seen to be continuous throughout working life and embrace personal growth at all stages of an individual's life. It is clear tat the future will belong to those who can acquire and apply knowledge and skills that the global markets demand. New generation of students will require regular updating of their knowledge, skills and competences. In this context, higher education institutions will be required to expand flexibility and innovative in learning and teaching.

Traditionally, universities had two main approaches of learning; deep approach and surface approach. Students who take deep approach to learning intend to understand the subject in a way that is personally meaningful, engaging their own experience and previous knowledge in an interactive process with relevant content, logic and existing evidence of the subject. Learning is essentially transformative experience in which the students make or construct personal meaning out of the shared meaning available (Light et al., 2009:p.52). Their intention is to understand ideas for themselves by constructing their own meaning. On the other hand, students who adopt a surface learning approach intend to use or reproduce the available meanings in an instrumental way to deal with course requirements. The students will use the meanings, but perceive them as alien and eternally imposed (Light et al., 2009:p.52). As such they often simply approached through memorisation or reproducing material course and there is no sustained personal engagement with student's own experience and their previous knowledge.

Similarly, universities had two main conception of teaching; teacher-focused and learning-focused. In the first conception, the lecturer regards the practice of teaching as an expert, imparts or transmits information to a passively receptive or compliant student. It is further described 'that the mass of students are passive recipients of the wisdom of single speaker' (Ramsden, 2003: p. 108). Teaching mainly rests in the content of the curriculum (Light et. al, 2009) and knowledge to be transferred to students at this level is seen unproblematic (Ramsden, 2003). The most noteworthy is the student learning is not a central concern of the teacher. Consistent with this view of how learning occurs, lecturers who use this theory of teaching will typically attribute any failure to learn to faults in the students (Ramsden, 2003). Biggs (1999) refers this as the 'blame-the-student' theory of teaching. According to Kramer et al. (2010), to promote collaborative learning, educators have to create specific teaching-learning processes within particular learning set ups supported by educational media-technology. Faculty members and institutions discern the need to store the 
intellectual asset produced by faculty in the course of preparing their lectures and make it available for students and colleagues. However it is argued that this practice only focuses only explicit knowledge.

The second conception focuses on the learner, and on promoting conceptual change. Teaching is comprehended as a process working cooperatively with learners to help them change their understanding (Ramsden, 2003). It is making student learning possible. Teaching involves finding about students' misunderstandings, intervening to change them and creating a context of learning that encourages students to engage with subject matter (Ramsden, 2003). Therefore good teaching consists of developing ways to help student's improve and change their conceptual understanding (Light et. al, 2009). In developing those practices, it recognizes that meaning and knowledge are outcomes constructed by students in an active dialogue within the socially rich situation of the course and programme.

Further, to add value to the lecture materials and textbook content it becomes significant to relate the content with research work, industry interfaces and projects to fully realize the significance and future prospects of subjects. Case studies, simulation games, role plays, brainstorming sessions, interview questions and frequently asked questions (FAQs) along with the theoretical knowledge will enhance comprehension amongst the students and facilitate them to attain improved tacit knowledge of the subject.

In summary, this discussion seeks to map some of the concepts of learning and teaching to the application of KM practices, with a view to setting agenda for the future. Universities have significant level of KM activities and it is important recognise these and use them as foundation for further development particularly in the area of learning and teaching. In today's rapidly-changing economic environment, the role of universities as providers of knowledge is greatly challenged. The important question which now arises is how KM can contribute to the HEI in the new economy.

While KM concept is potentially related to learning and teaching in HEI evidences have shown that KM has been applied in industry for knowledge sharing and transfer. For instance, the management consulting firm McKinsey formed internal groups of experts called 'practices' to collect and distil experience gained in particular fields, such as manufacturing and energy, and to communicate industry and project specific knowledge to others in the firm. Other firms develop collaborative relationships with educational institutions that enable the institutions to provide industry specific training. Ford, General Motors and Chrysler, for example, in conjunction with industry and local university, have established the Michigan Virtual Automotive College, to raise the levels of industry-specific education among automotive industry workers (Probst et al., 2000). British Aerospace has linked with a number of UK universities to both deliver and accredit training from its 'virtual university'. In addition, organisations can arrange for staff to complete distance-based or learning programmes. Where specialist tacit knowledge is required, an expanding role can be envisaged for retired professionals to provide mentoring services to staff in the organisations. On the other hand, granting university qualifications through the new form of work-based learning credential requires partnering arrangements among organisations, universities and individual participants. 


\section{Macrothink}

International Journal of Learning and Development

ISSN 2164-4063 2019, Vol. 9, No. 1

It involves the recognition of learning that occurs in workplaces in ways that enable the transformation of tacit knowledge, everyday 'know-how' into observable and accessible knowledge (Psarras, 2006). What someone does at work can be turned into areas of learning to acquire academic credit. In summary this demonstrates ways of applying KM to learning and teaching in organisations in view to establish KM practices in HEI.

\section{Proposed Hybrid Framework}

This section draws from the main findings both literature in $\mathrm{KM}$ and learning and teaching to develop a conceptual framework in order to provide a profound and comprehensive understanding the implications of KM in education learning and teaching. In view to assess the implication and challenges that HEI face in embedding KM practices, two types of KM perspectives are used as a lens through which to view 1) learning concepts; deep and surface approach and 2) teaching concepts; teacher-focused, and learning-focused. This section provides the description of the framework and discusses how it can be applied in HEI. As shown in Figure 1.1, the framework provides a sense of understanding illustrate how KM applications could benefit learning and teaching practices. This framework graphically encapsulates and assembles all of the elements in simplified fashion based on the findings that were discussed in previous section. The illustration is only conceptual based on the interpretations from the findings of the literature. 




Figure 1. Hybrid Framework

As illustrated in Figure 1.1, it can be seen that the framework would be integrated into the strategy. As a starting point, the HEI should have a strategy to achieve the HEI's objective through KM practices. The strategy should be made visible to staff-students so as to make knowledge sharing directly part of HEI strategy. In general, a certain level of strategic endeavour is required to implement KM practices. It was discovered from the literature that KM initiatives were implemented towards strategic endeavour to achieve business objectives. Basically, organisations need to have a clear picture of what they want to achieve and consider how KM can effectively deliver their desired outcomes. In business, KM implementation being tied to the business strategy was stressed in the literature by Davenport and Prusak (1998), Zack (1999) and Chait (1999). Chait (1999:p.24) indicates the importance of this linkage by stating that in many ways managing knowledge is no different from managing other aspects of an organisation: firstly, there must be a vision that links with the organisation's objectives and strategies; second, people must be aligned to that vision; and third, the alignment must come from the top-down and across all of the organisation. This suggests that KM should not be implemented as an end in itself or just 'nice-to-have', as KM is criticised of being implemented due to the bandwagon effect. In short, business strategy and objectives are tied to KM practices, making them the logical starting point for KM implementation and thus ensuring that those 
$\mathrm{KM}$ and business strategies do not exist in isolation. Given that $\mathrm{KM}$ is related to two perspectives; tacit and explicit knowledge, HEI also needs certain strategies to utilise both of these knowledge for the benefit of learning and teaching. For example, if surface approach (explicit knowledge) is adopted lecturer will focus on completing the content of subject unreflectively and the assessment based on the memorising the facts and figures. However, if deep approach (tacit knowledge) is adopted in teaching practices lecturer will relate the previous knowledge to new knowledge and the assessment including learning conversations and scenario planning.

From the discussions in previous section, it can be claimed that $\mathrm{KM}$ is implemented either from IT approach or in terms of cultural approach. The findings of the discussion revealed that there are strengths and weaknesses in both of the KM approaches available for KM implementation. To overcome such difficulties, a conceptual framework was developed which is applicable to KM practices in HEI with a balanced view of both KM perspectives which can help educators and academics staff to implement or evaluate their learning and teaching practices focusing on hybrid approach.

The experience from KM practitioners highlight that the company actually deploys a hybrid approach in some way or other. The KM implementation activities in some companies are not confined to one particular approach, be it IT approach (technological-related) or cultural approach (people-related). It might happen that people-related approach is followed by another technology related approach or vice-versa. That is, knowledge may be created with verbal discussions and end up with formal comments which may be in written form of documentation.

Similarly in HEI, for instance in learning approach, the same student learns differently in different situations. What constitutes an approach to learning, surface or deep, varies according to academic task. For example, an initially narrow concentration on detail and logical connections as part of deep approach is common in subjects which is cumulative, paradigmatic, replicable and capable of being summarised in terms of general of laws i.e. physics; while in subjects usually described being particularistic, idiographic and reinterpretive i.e. history a deep approach is more likely to involve the student in stressing, right from the start, an intention to elucidate material in a personal way (Ramsden,2003:p.50). In describing surface approaches, students of science are more likely to speak of narrow focus on techniques, procedures and formulae, while humanities and social scientists tend to report a more generalised and vague approach, which frequently includes oversimplification of main ideas in reading and essay writing, or memorising unrelated generalities in preparations for examinations (Ramsden, 2003:p. 50).

In terms of conception of teaching, the most complex issue therefore includes aspects of both the others. In other words, teaching does involve transferring knowledge and presenting information (teacher-focused); and also facilitating students in generating knowledge for themselves (student-focused and learning-focused). It should be noted that the variation between these categories conception of teaching are applied in one way or another as teachers always deploy lecture technique (transmitting knowledge) in the beginning of the module and eventually use small group and active learning techniques (creating knowledge) as the 
semester progresses. In short, this discussion demonstrates that both learning and teaching concepts is embedded by the two perspectives of $\mathrm{KM}$ practices, i.e. objectivist-based perspective that largely depends on IT utilisation - associated with surface approach in learning and teacher-focused in teaching, and practice-based perspective that focus on people involvement - associated with deep approach in learning and, student and learning-focused in teaching. The most noteworthy is that although tacit knowledge does not play such a dominant role in surface learning and teacher-focused approach, explicit knowledge is an important component of knowledge required student's learning and teaching purposes. Similarly, to some extent, the process occurs in deep learning and, student and learning-focused approach. The practice-based KM perspective comes into play when tacit knowledge is generated within student's learning and teaching process. This shows how the interactive process of those KM perspectives 'activates' the process of learning and teaching respectively. The most substantial issue is that although those $\mathrm{KM}$ perspectives seem to contradict each other on a theoretical level, it is important to recognise that both perspectives appear to be complementary in reality. Thus, the development of a conceptual framework is applicable to HEI with a balanced view of both perspectives, which can help academic practitioners to implement or evaluate their learning and teaching practices, either focusing on technological or human-based and even hybrid approaches from KM point of view. A successful integrated hybrid approach is one that takes advantage of the positive features of both IT and cultural approach. In other words, the proposed approach located somewhere between the rather divergent approaches and recognises the interplay between both approaches.

\section{Concluding Perspective}

A KM perspective is a crucial consideration in enhancing the effectiveness and efficiency of teaching and learning in HEI. KM initiatives in teaching and learning can be used as part of the institutional strategies to create, transform, store and disseminate knowledge according to the needs of the students and learners.

The KM practices in industry are seen as innovative development that can be applied in HEI. This is illustrated in Figure 1.1 which displays KM embedded in learning and teaching incorporating hybrid approach. Using the proposed KM implementation, as the starting point, HEI should have strategy to achieve the added value of KM practices by utilising both 'IT' (associated with surface approach in learning and teacher-focused in teaching), and 'cultural' approach (associated with deep approach in learning and, student and learning-focused in teaching).

There has indeed been a paradigm shift in HEI. The teaching-learning process cannot be confined only to the contents in the textbook so called explicit knowledge only. The needs of the industry and competition require academicians and students to be equipped with both explicit and tacit knowledge of their subjects from cross platform perspectives. The proposed framework can be used as a model to develop institutional teaching and learning KM models based on the inputs of courses offered, curriculum, industry requirements, research activities and the overall academic environment of the institution. With respect to IT, the framework is a significant knowledge enabler. This can be explained in terms of the potential of IT 
infrastructure in facilitating KM processes by providing a platform for knowledge acquisition, storage and dissemination, supporting collaboration among students and fostering centered, real time, integrated systems.

Drawing from organisational experience, certainly, IT supports the KM process at a certain level. However, in response to the limitations of the IT role in KM practices, the involvement of people is identified as crucial to ensure the success of KM implementation, particularly to acquire and share tacit knowledge. It is not to undermine the role of IT but rather to stress that organisational knowledge is complex, rich and embedded in contexts which require human intervention. In relation to people involvement, the organisational culture is identified as an important element in managing knowledge. Given that knowledge creation and sharing are stressed as social activities taking place among people, organisations require a supportive and collaborative culture, including reshaping the positive attitudes and behaviours of people towards KM practices. In sum, to build and develop a robust and thriving knowledge environment in teaching-learning process, the institutions need to foster the overall culture of sharing and managing knowledge.

The conclusion that can be drawn from this is that KM should be implemented with a hybrid approach comprising strategy, IT (surface approach/teacher-focused) and organisational culture (deep approach/student-focused, learning-focused). If any of these elements are not attended to, it may be the case that the KM initiative is not complete which may lead to the unsuccessful of KM implementation in HEI.

\section{References}

Ahmed, P. K., Lim, K. K., \& Loh, A. Y. E. (2002). Learning Through Knowledge Management. Butterwort Heinemann, Oxford.

Alavi, M., \& Leidner, D. E. (2001). Review: Knowledge Management and Knowledge Management Systems: Conceptual Foundations and Research Issues. MIS Quarterly, 25(1), 107-136.

Allee, V. (1999), The art and practice of being revolutionary. Journal of Knowledge Management, 3(2), 121-131. https://doi.org/10.1108/13673279910275576

Alvesson, M., \& Karreman, D. (2001). Odd Couple: Making Sense of the Curious Concept of Knowledge Management. Journal of Management Studies, 38(7), 995-1018. https://doi.org/10.1111/1467-6486.00269

Assudani, R. H. (2005) Catching the chameleon: Understanding the elusive term knowledge. $\begin{array}{llll}\text { Journal of Knowledge } \quad \text { Management, } & 9(2), & 31-44 .\end{array}$ https://doi.org/10.1108/13673270510590209

Bahra, N. (2001). Competitive Knowledge Management. Palgrave, New York. https://doi.org/10.1057/9780230554610

Bartol, K. M., \& Srivastava, A (2002), Encouraging Knowledge Sharing: The Role of Organizational Reward Systems. Journal of Leadership and Organization Studies, 9(1), 
64-76. https://doi.org/10.1177/107179190200900105

Benbya, H., \& Belbaly, N. A. (2005). Mechanisms for Knowledge Management Systems Effectivenes: An Exploratory Analysis, Knowledge and Process Management, 12(3), 203-216. https://doi.org/10.1002/kpm.231

Bhusry, M., \& Ranjan, J. (2012). Enhancing the teaching - learning process: a knowledge management approach. International Journal of Educational Management, 26(3), 313-329. https://doi.org/10.1108/09513541211213372

Biggs, J. B. (1999). Teaching for Quality Learning at University. SRHE and Open University Press, Buckingham.

Binney, D. (2001). The Knowledge Management Spectrum - understanding the KM landscape. Journal of Knowledge Management, 5(1), 33-42. https://doi.org/10.1108/13673270110384383

Blackler F (1995), Knowledge, Knowledge Work and Organizations: An Overview and Interpretation. Organization $\quad$ Studies, $\quad 6(6), \quad$ 1021-1046. https://doi.org/10.1177/017084069501600605

Bollinger, A. S., \& Smith, R. D. (2001). Managing organizational knowledge as strategic asset. Journal of Knowledge Management, $\quad 5(1), \quad 8-18$. https://doi.org/10.1108/13673270110384365

Breu, K., Grimshaw, D., \& Myers, A. (2000). Releasing the Value of Knowledge: A Survey of UK Industry. Cranfield School of Management.

Breu, K., Grimshaw, D., \& Myers, A. (2000). Releasing the Value of Knowledge: A Survey of UK Industry. Cranfield School of Management.

Brown, J. S., \& Duguid, P. (2001). Knowledge and Organization: A Social-Practice $\begin{array}{llll}\text { Perspective. } \quad \text { Organization } & \text { Science, } & 12(2), & 198-213 .\end{array}$ https://doi.org/10.1287/orsc.12.2.198.10116

Calkins, S., \& Light, G. (2008), Promoting student-centred teaching through a project-based faculty program. To Improve the Academy 26, 217-229.

Carlucci, D., \& Schiuma, G. (2006). Knowledge Value Spiral: Linking Knowledge Assets to Company Performance. Knowledge and Process Management, 13(1), 35-46. https://doi.org/10.1002/kpm.243

Chait, L. P. (1999). Creating a successful knowledge management system. Journal of Business Strategy, 20(2), 23-26. https://doi.org/10.1108/eb039991

Chauvelle, D., \& Despres, C. (2002). A review of survey research in knowledge management: 1997-2001. Journal of Knowledge Management, 6(3), 207-223. https://doi.org/10.1108/13673270210434322

Cook, S. D. N., \& Brown, J. S. (1999). Bridging Epistemologies: the Generative Dance 
between Organizational Knowledge and Organizational Knowing. Organization Science, 10 (4), 381-400. https://doi.org/10.1287/orsc.10.4.381

Cook, S. D. N., \& Brown, J. S. (1999). Bridging Epistemologies; the Generative Dance between Organizational Knowledge and Organizational Knowing. Organization Science, 10(4), 381-400. https://doi.org/10.1287/orsc.10.4.381

Davenport, T. H., \& Prusak, L. (1998). Working Knowledge: Managing What Organization Knows. Harvard Business School Press, Boston, MA.

Davenport, T. H., \& Prusak, L. (1998). Working Knowledge: Managing What Organization Knows. Harvard Business School Press, Boston, MA.

Drucker, P. F. (1994). Post-Capitalist Society. Harper Business, New York.

Drucker, P. F. (1998). The Coming of the New Organization, In Harvard Business Review on Knowledge Management. Harvard Business School Press, MA.

Drucker, P. F. (1998). The Coming of the New Organization, In Harvard Business Review on Knowledge Management. MA: Harvard Business School Press.

Edwards, J. S., Handzic, M., Carlsson, S., \& Nissen, M. (2003) Knowledge management research \& practice: visions and directions. Knowledge Management Research \& Practice, 1, 49-60. https://doi.org/10.1057/palgrave.kmrp.8500005

Edwards, J. S., Handzic, M., Carlsson, S., \& Nissen, M. (2003). Knowledge management research \& practice: visions and directions. Knowledge Management Research \& Practice, 1, 49-60. https://doi.org/10.1057/palgrave.kmrp.8500005

Empson, L. (2001), Introduction: Knowledge Management in Professional Service Firms. Human Relations, 54(7), 811-817. https://doi.org/10.1177/0018726701547001

Entwistle, N. (2005). Contrasting perspectives on learning, In Marton F et al. (Eds), The experience of Learning, Originally published Edinburgh. Scottish Academic Press, republished Edinburgh: Centre for Teaching, Learning and Assesment.

Fahey, L., \& Prusak, L. (1998). The Eleven Deadliest Sins of Knowledge Management. California Management Review, 41(3), 265-276. https://doi.org/10.2307/41165954

Firestone, J. M. (2003). Key issues in the new knowledge management. Butterworth-Heineman, Boston, MA.

Frappaolo, C., \& Wilson Todd, L. (2000). After the Gold Rush: Harvesting Corporate Knowledge Resources, 14 Oct. Retrieved from www.intelligentkm.com

Goddard, A. (1998), Facing up to market forces. Times Higher Educational Supplement, 13, Nov, 6-7.

Grant, R. M. (1996), Toward a Knowledge-Based Theory of the Firm. Strategic Management Journal, 17(Special Issue), 109-122. https://doi.org/10.1002/smj.4250171110 


\section{Macrothink}

International Journal of Learning and Development

ISSN 2164-4063 2019, Vol. 9, No. 1

Grant, R. M. (1996). Toward a Knowledge-Based Theory of the Firm. Strategic Management Journal, 17(Special Issue), 109-122. https://doi.org/10.1002/smj.4250171110

Hansen, M. T., Nohria, N., \& Tierney, T. (1999). What's your strategy for managing knowledge. Harvard Business Review, Mar-Apr, 106-116.

Hansen, M. T., Nohria, N., \& Tierney, T. (1999). What's your strategy for managing knowledge. Harvard Business Review, Mar-Apr, pp. 106-116.

Hislop, D. (2005). Knowledge Management in Organisations. Oxford University Press, New York.

Hlupic, V., Pouloudi, A., \& Rzevski, G. (2002). Towards an Integrated Approach to Knowledge Management: 'Hard', 'Soft' and 'Abstract' issues. Knowledge and Process Management, 9(2), pp. 90-102. https://doi.org/10.1002/kpm.134

Kakabadse, N. K., Kakabadse, A., \& Kouzmin, A. (2001). From tacit knowledge to knowledge management: Leveraging Invisible Assets, Knowledge and Process Management, 8(3), 137-154. https://doi.org/10.1002/kpm.120

Kakabadse, N. K., Kakabadse, A., \& Kouzmin, A. (2003). Reviewing the knowledge management literature: towards a taxonomy. Journal of Knowledge Management, 7(4), 75-91. https://doi.org/10.1108/13673270310492967

KPMG Consulting. (2000). Knowledge Management Research Report [online]. Retrieved 15th Oct., 2004, from http://www.kpmg.com

Kramer, B. J., Klebl, M., \& Zobel, A. (2010). Sharing educational knowledge and best practices in edu-sharing. Proceedings of the 2010 Second International Conference on Mobile, Hybrid and On-Line Learning, Saint Maarten, 10-16 February, pp. 53-9. https://doi.org/10.1109/eLmL.2010.27

Leornard-Barton, D. L. (1995). Wellsprings of knowledge: building and sustaining the sources of innovation. Harvard Business School Press, Boston, MA.

Liebowitz, J. (1999). Knowledge Management Handbook. CRC Presss, Boca Raton, Florida.

Liebowitz, J. (2000). Building Organizational Intelligence: A Knowledge Management Primer. Boca Raton, Florida: CRC Press.

Light, G., Cox, R., \& Calkins, S. (2009). Learning and Teaching in Higher Education (2nd ed.). Sage, London.

Malhotra, Y. (1998). Deciphering the Knowledge Management Hype. The Journal for Quality and Participation, Cincinnati, 21(4), 58-60.

Management Review \& AMA Research. (1999). Survey on Knowledge Management, Management Review. April, 20-26.

McAdam, R., \& McCreedy, S. (1999). The process of knowledge management within organizations: a critical assessment of both theory and practice. Knowledge and Process 
Management,

$6(2)$

101-113.

https://doi.org/10.1002/(SICI)1099-1441(199906)6:2<101::AID-KPM53>3.0.CO;2-P

McDermott, R. (1999). Why Information Technology Inspired But Cannot Deliver Knowledge Management. California Management Review, 41(4), 103-117. https://doi.org/10.2307/41166012

McDermott, R., \& O'Dell, C. (2001). Overcoming cultural barriers to sharing knowledge. Journal of Knowledge Management, $\quad$ 5(1), 76-85. https://doi.org/10.1108/13673270110384428

McElroy, M. (2003). The New Knowledge Management: Complexity, Learning, and Sustainable Innovation. Butterworth-Heinemann, MA.

McElroy, M. (2003). The New Knowledge Management: Complexity, Learning, and Sustainable Innovation. Butterworth-Heinemann, MA.

Metaxiotis, K., Ergazakis, K., \& Psarras, J. (2005). Exploring the world of knowledge management: agreements and disagreements in the academic/practitioner community. Journal of Knowledge Management, 9(2), 6-18. https://doi.org/10.1108/13673270510590182

Miles, M. B., \& Huberman, A. M. (1994). Qualitative Data Analysis (2nd ed.). Sage, California.

Moffett, S., McAdam, R., \& Parkinson, S. (2003). An empirical analysis of knowledge management applications. Journal of Knowledge Management, 7(3), 6-26. https://doi.org/10.1108/13673270310485596

Moffett, S., McAdam, R., \& Parkinson, S. (2004). Technological Utization for Knowledge Management. Knowledge \& Process Management, 11(3), 175-184. https://doi.org/10.1002/kpm.201

Newell, S., Robertson, M., Scarbrough, H., \& Swan, J. (2002). Managing Knowledge Work. Palgrave Macmillan, New York.

Newell, S., Robertson, M., Scarbrough, H., \& Swan, J. (2002). Managing Knowledge Work. Palgrave Macmillan, New York.

Nonaka, I., \& Takeuchi, H. (1995). The Knowledge Creating Company. Oxford University Press, New York.

Nonaka, I., Umemoto, K., \& Sasaki, K. (1998). There Tales of Knowledge-Creating Companies. In von Krogh, Roos, J., and Kleine, D. (Eds), Knowing in Firms: Understanding, Managing and Measuring Knowledge. London: Sage Publications.

Pan, S. L., \& Scarborough, H. (1999), Knowledge Management in Practice: An Explanatory Case Study. Technology Analysis \& Strategic Management, 11(3), 359-374. https://doi.org/10.1080/095373299107401

Probst, G., Raub, S., \& Romhardt, K. (2000), Managing Knowledge: Building Blocks for 
Success. John Wiley \& Sons, England.

Probst. G., Raub, S., \& Romhardt, K. (2000). Managing Knowledge: Building Blocks for Success. John Wiley \& Sons, England.

Psarras, J. (2006). Education and training in the knowledge-based economy. VINE: The Joournal of Information and knowledge information systems, 36(1), 85-96.

Ramsden, P. (2003). Learning to Teach in Higher Education (2nd ed.). RoutledgeFlamer, New York. https://doi.org/10.4324/9780203507711

Ribiere, V., \& Sitar, A. (2003). Critical role of leadership in nurturing a knowledge supporting culture. Knowledge Management Research \& Practice, 1(1), 39-48. https://doi.org/10.1057/palgrave.kmrp.8500004

Rowley, J. (2000). Is higher education ready for knowledge management?, The International Journal of Educational Management, 14(7), 325-333. https://doi.org/10.1108/09513540010378978

Ruggles, R. (1998), The State of the Notion: Knowledge Management in Practice. California Management Review, 40(3), 80-89. https://doi.org/10.2307/41165944

Ruggles, R. (1998). The State of the Notion: Knowledge Management in Practice. California Management Review, 40(3), 80-89. https://doi.org/10.2307/41165944

Ruikar, K., Anumba, C., \& Egbu, C. (2007). Intergrated use of technologies and techniques for construction knowledge management. Knowledge Management Research \& Practice, 5(4), 297-331. https://doi.org/10.1057/palgrave.kmrp.8500154

Sarvary, M. (1999). Knowledge Management and Competition in the Consulting Industry. California Management Review, 41(2), 95-107. https://doi.org/10.2307/41165988

Scarborough, H., \& Swan. (1999). Knowledge Management: A Literature Review. Institute Personnel and Development, Cromwell Press, UK.

Schein, E. H. (2004). Organisational Culture and Leadership (3rd ed.). Jossey Bass, CA.

Sheehan, T., \& Poole, D. (2005). The Business Case for Knowledge Management, In C. J. Anumba, C. Egbu, \& P. Carillo, (Eds.), Knowledge Management in Construction (pp. 60-62). Blackwell Publishing, Oxford, UK. https://doi.org/10.1002/9780470759554.ch4

Stewart, T. A. (1998). Intellectual Capital: The New Wealth of Organization. Nicholas Brealey Publishing, Great Britain.

Strassman, P. A. (1997). The Squandered Computer: Evaluating the Business Alignment of Information Technologies. Information Economic Press, USA.

Sveiby, K. E. (2001). The New Organisational Wealth: Managing and Measuring Knowledge-Based Assets. Barrett-Kohler, San Francisco, CA

Tsoukas, H. (2005). Complex Knowledge: Studies in Organizational Epistemology. Oxford 


\section{Macrothink}

Press, New York.

Tsui, E. (2005). The role of IT in KM: where are we now and where are we heading? Journal of Knowledge Management, 9(1), 3-6. https://doi.org/10.1108/13673270510584198

Uit Beijeirse, R. P. (1999). Questions in knowledge management: defining and conceptualising a phenomenon. Journal of Knowledge Management, 3(2), 94-109. https://doi.org/10.1108/13673279910275512

Venzin, M., von Krogh, G., \& Roos, J. (1998), Future research into Knowledge Management, In von Krogh, Roos, J., and Kleine, D. (Eds), Knowing in Firms: Understanding, Managing and Measuring Knowledge. London: Sage Publications.

Venzin, M., von Krogh, G., \& Roos, J. (1998). Future research into Knowledge Management, In Knowing in Firms: Understanding, Managing and Measuring Knowledge (von Krogh, Roos J and Kleine D, Eds), 26-66, Sage Publications, London.

Wah, L. (1999). Behind The Buzz, Management Review 88 (4), 16-26.

Walsham, G. (2001). Knowledge Management: The Benefits and Limitations of Computer Systems. European Management Journal 19(6), 599-608. https://doi.org/10.1016/S0263-2373(01)00085-8

Walsham, G. (2001). Knowledge Management: The Benefits and Limitations of Computer Systems. European Management Journal, 19(6), 599-608. https://doi.org/10.1016/S0263-2373(01)00085-8

Zack, M. H. (1999), Developing a Knowledge Strategy. California Management Review, 41 (3), 125-145. https://doi.org/10.2307/41166000

Zuboff, S. (1988). In the Age of Smart Machine: The Future of Work and Power. Heinemann Professional, Oxford.

\section{Copyright Disclaimer}

Copyright for this article is retained by the author(s), with first publication rights granted to the journal.

This is an open-access article distributed under the terms and conditions of the Creative Commons Attribution license (http://creativecommons.org/licenses/by/4.0/). 